Business and Economics Research Journal

Volume 8 Number 42017

pp. 661-672

ISSN: $1309-2448$

DOI Number: 10.20409/berj.2017.74

\title{
Kyoto Protokolünün Karbon Emisyonu Üzerine Etkisi: Kırılmalı Panel Birim Kök Analizi ${ }^{1}$
}

\author{
Mehmet Mert ${ }^{\mathrm{a}}$
}

\author{
Abdullah Emre Çağlar ${ }^{b}$
}

\begin{abstract}
Öz: Karbon emisyonu 1997 yılında imzalanan Kyoto protokolü gibi uluslararası anlaşmalara rağmen küresel ölçüde artmaya devam etmektedir. 2005 yılında yürürlüğe giren Kyoto anlaşmasının, anlaşmayı imzalayan ülkelerin karbon emisyonu serilerinde anlamlı kırımalara yol açıp açmadığı çalışmanın temel amacını oluşturmaktadır. Analiz 26 Kyoto ülkesi için 1960-2013 yıllarını kapsamaktadır. Öncelikle birinci nesil birim kök testleri yapılmış ve incelenen 26 Annex ülkesinden oluşan Kyoto panelinde kişi başı karbon salımı serileri durağan dışı bulunmuştur. Daha sonra yatay kesit bağımlılı̆ı test edilmiş ve yatay kesit bağımılı̆ı̆ının olduğuna karar verilmiştir. Sonuç olarak yatay kesit bağımlıı̆̆ı altında yapısal kırılmaları da dikkate alan birim kök testi uygulanmıştr. Elde edilen bulgulara göre, birinci nesil panel birim kök testlerinin aksine, Kyoto ülkelerinde kişi başına düşen karbon emisyonu değişkeni durağan bir sürȩ izlemektedir. Ayrıca kırılma zamanları incelenen ülkeler için, 26 Kyoto ülkesinin 19'unda, Kyoto antlaşmasının etkisinin gözlemlenebileceği 1997-2005 yılları arasında kırılmalar görülmektedir. Dolayısıyla serilerde anlamlı kırılmalar ve Kyoto protokolünün anlaşmayı imzalayan ülkeler açısından karbon emisyonu üzerinde anlamlı bir etkisinin olduğu tespit edilmiştir.
\end{abstract}

Anahtar Sözcükler: Kyoto Protokolü, Karbon Emisyonu, Panel Birim Kök, Yapısal Kırılma, Yatay Kesit Bağımlılığı

JEL Sınıflandırması: C40, C50, Q54

\section{Impact of Kyoto Protocol on Carbon Emissions: An Application of Panel Unit Root Tests with Structural Breaks}

\begin{abstract}
Carbon emissions have contiunued to increase globally, in despite of joint efforts to implement international agreements such as Kyoto protocol since 1997. The main subject of the current study is to investigate significant or insignificant structural breaks on carbon emission series of the Kyoto countries. The data periyod of the study is between 1960 and 2013 for 26 Kyoto countries. First of all, the first generation panel unit root tests have been performed and carbon emissions have been found as nonstationary. Then, cross-sectional dependency have been tested and Kyoto panel has been stated as cross-sectional dependent. So, panel unit root tests with structural breaks under cross-sectional dependency has been performed. Unlike the results of the first generation panel unit root tests, stationary process has been revealed. Beside this, in 19 of 26 Kyoto countries, the structural breaks between 1997-2005 have been observed as Kyoto protocol affects. As a result of the study, significant structural breaks in Kyoto panel have been stated and the impact of the Kyoto protocol on carbon emission series for the Kyoto countries is significant.
\end{abstract}

Keywords: Kyoto Protocol, Carbon Emissions, Panel Unit Root, Structural Breaks, Cross-Sectioanal Dependence

JEL Classification: C40, C50, Q54

\footnotetext{
${ }^{a}$ Assoc. Prof., PhD., Akdeniz University, Faculty of Economics and Administrative Sciences, Department of Econometrics, Antalya, Turkiye,mmert@akdeniz.edu.tr

${ }^{\mathrm{b}}$ Res. Asst., Akdeniz University, Faculty of Economics and Administrative Sciences, Department of Econometrics, Antalya, Turkiye, aecaglar@akdeniz.edu.tr
} 


\section{Giriş}

İklim değişikliği 21. yüzyılda insanlığın en önemli sorunlarından biri olarak görülmektedir. Bu nedenle, küresel sera gazı salımını azaltmayı hedefleyen uluslararası anlaşmalar önem kazanmaktadır. İklim değişikliğinin en önemli sonucu olarak küresel ısınmanın nedeni atmosfere salınan toplamsal birçok farklı sera gazı olsa da, karbon dioksit $\left(\mathrm{CO}_{2}\right)$ gazının diğer gazlardan çok daha fazla olması nedeniyle ülkeler için $\mathrm{CO}_{2}$ gazının salımının azaltııması temel hedef olmaktadır. Bu amaç doğrultusunda uluslararası bir anlaşma olan Kyoto protokolü 1997 yılında birçok ülke tarafindan imzalanmış ve 2005 yılında yürürlüğe girmiştir. Kyoto protokolüne göre Birleşmiş Milletler İklim Değişikliği Çerçeve Sözleşmesini (United Nations Framework Convention on Climate Change-UNFCCC) imzalayan endüstrileşmiş ülkeler (Annex-ı ülkeleri) karbon salımlarını 2012 yılına kadar 1990 seviyelerinin \%5.2'si düzeyinde azaltmalarını taahhüt etmişlerdir (UNFCCC, 2015). UNFCCC altnndaki ülkeler, içerisinde Avrupa Birliği ülkeleri de olan ve "gelişmiş ülkeler (Annex-II ülkeleri)", "geçiş aşamasındaki ülkeler" ve "diğerleri" olmak üzere üç gruba ayrılmışlarıdır. Annex-II ülkeleri 24 gelişmiş ülkeden oluşmakta ve iklim değişikliğinin olası etkilerini yönetmenin dışında diğer ülkelere karbon emisyonlarını azaltmaları ve iklim değişikliği ile mücadele için finansal ya da teknik destek vermekle yükümlüdürler.

2015 yılında imzalanan Paris anlaşmasına kadar; 2007 yılında aynı zamanda Kyoto ülkesi olan Avrupa Birliği ülkelerince kabul edilen ve içerisinde ciddi sera gazı azaltım hedefleri bulunduran enerji ve iklim değişikliği paketi gibi anlaşmalar sayılmaz ise; Kyoto protokolü küresel sera gazı salımı azaltımı konusunda imzalanan en rekabetçi ve en spesifik hedefleri olan bir anlaşma olmuştur (Kumazawa ve Callagan, 2012). Kyoto ülkelerinin büyük bölümünün Avrupa ülkeleri olması, Avrupa ülkelerinin ayrıca kendi aralarında azaltım hedefleri koymasına rağmen; 1997 'den bu yana $\mathrm{CO}_{2}$ salımı küresel düzeyde artmaya devam etmiştir. Dünya bankası 2015 raporuna göre 1990'da 22.4 milyon tmt (thousand mtric tons) olan $\mathrm{CO}_{2}$ salımı 2011'de 36.4 milyon tmt'ye ulaşmıştır (WB, 2015). Dahası, 1990 yılında kişi başı karbon salımı 4.2 metrik ton iken 2011 yıında \%17 artarak 4.9 metric tona ulaşmıştır. Bu sonuçlardan birçok ülkenin sera gazı azaltım hedeflerinin çok uzağında olduğu ortaya çıkmaktadır.

Birçok çalışma ekonomik büyüme ile sera gazı emisyonları arasındaki ilişkiye odaklamıştır. Çevresel Kuznets Eğrisi (ÇKE) hipotezinin geçerliliğini sınayan çalışmalar ekonomik büyümenin salımlar üzerindeki tersU şeklindeki ilişkisinin geçerliliğini test etmektedir (Grossman ve Kruger, 1991, 1994; Shafik, 1994; Selden ve Song, 1994; Holtz-Eakin ve Selden, 1995; Bölük ve Mert, 2014, 2015; Mert ve Bölük, 2016). ÇKE hipotezi ile beraber enerji tüketiminin, uluslararası ticaretin, doğrudan yabancı yatıııların ve yenilenebilir enerjinin karbon salımları üzerine etkilerini araştıran bir çok çalışma söz konusudur (Apergis ve Payne, 2009; Halicioglu, 2009; Sadorsky, 2009; Marrero, 2010; Pao ve Tsai, 2011; Suleiman vd, 2013; Chandran ve Tang, 2013; LopezMenenedez vd., 2014; Kivyiro ve Arminen, 2014; Bölük ve Mert, 2015; Bastola ve Sapkota, 2015; Çağlar ve Mert, 2017). ÇKE hipotezine ilişkin bu çalışmalar ekonomik değişkenlerle salımlar arasındaki ilişkilere yönelik yararlı bilgiler sunarken $\mathrm{CO}_{2}$ salımlarının davranışı ve salımların Kyoto protokolünden nasıl etkilendikleri konusunda hiç bir ipucu vermemektedir. Literatüre bakıldığında Kyoto protokolünün emisyonlar üzerindeki etkilerini ortaya çıkaran yeteri kadar ampirik çalışmanın olmadığı görülmektedir.

Bu çalışmanın asıl amacı şu soruya bir cevap bulmaktır: Kyoto protokolünün global sera gazı emisyonunun azaltılmasına olan etkisi nedir? Sera gazı emisyonunun artı̧ı ve sonucunda iklim değişikliğinin gezegenin önündeki en önemli sorunlardan biri haline gelmesi ve bu sorunun ancak uluslararası anlaşmalarla çözülebilecek olması Kyoto protokolü gibi anlaşmaların etkisinin bilinmesinin özellikle sonraki anlaşmalara ışık tutması açısından önemi vardır. 2015 yılında imzalanan ve 2020 yılında yürürlüğe girecek olan Paris anlaşması ile beraber Kyoto protokolü geçerliliğini yitirmiştir ancak bir anlaşmanın etkisini ekonometrik olarak ölçebilmek için yürürlüğe girip belli bir zaman geçmesi gereklidir. Böylece Paris anlaşmasının etkilerini şimdiden ekonometrik olarak görebilmek mümkün olmamakla beraber Kyoto protokolünün etkisini ölçmek mümkündür. Küresel iklim değişikliğini önlemek için yapılan uluslararası anlaşmaların küresel karbon salımının azaltılmasına olan etkilerinin bilinmesi ise sonraki anlaşmalarda taraflar açısından son derece önemli olacağı düşünülmüştür. Sonuç olarak 1960-2013 dönemi yıllık olarak verilerine ulaşılabilen 26 Kyoto ülkesinin kişi başı karbon emisyonları analiz edilmiş ve elde edilen veri setine panel kırılmalı birim kök testi yapılmıştır. Panelin durağanlığı ve hangi yıllarda yapısal kırılmalar meydana geldiği incelenmiştir. Çalışmanın 
ikinci bölümünde yapılan literatür taraması özetlenmiştir. Üçüncü bölümünde veri seti ve uygulanan ekonomerik metodoloji tanıtılmış, dördüncü bölümde ampirik bulgular elde edilmiş, beşinci ve son bölümde elde edilen sonuçlar tartş̧ılmıştır.

\section{Literatür Taraması}

Karbon salımının küresel ısınmaya yol açtığı çok sayıda ampirik çalışmayla desteklenmektedir (Sun ve Wang, 1996). Sonuç olarak küresel ısınmanın negatif etkilerini azaltmak için karbon salımını azaltmak uluslararası bir amaç olmaktadır. Eğer başarılırsa, Kyoto protokolü küresel saragazı salımlarının 1990 öncesi seviyelere çekecektir. Ancak salımların küresel düzeyde artmaya devam etmesi Kyoto'nun bu amacından uzaklaştiğının bir göstergesidir. Bazı araştırmacılar Kyoto protokolünün artı ve eksilerini tartışırlarken bazı araştırmacılar protokolün yeniden revize edilip salımların azaltılması yönünde daha güçlü bir anlaşmanın imzalanması gerektiğini öne sürmüşlerdir (Swinton ve Sarkar, 2008; Huang vd., 2008; Almedia ve Carvalho, 2009).

Kyoto protokolü çok önemli bir uluslararası anlaşma olmasına rağmen; Kyoto ülkelerinin sera gazı azaltım performansları üzerine Kyoto'nun etkisinin incelendiği çok az çalışmaya rastlanmaktadır. Korhonen ve Savolainen (1999), Birleşmiş Milletler İklim Değişikliği Çerçeve Sözleşmesinin karbon emisyonu üzerine etkisini karbon döngü modeli (carbon cycle model) yardımıyla incelemiş ve gelişmiş ülkelerin her hangi bir azaltım hedefi koymaksızın fosil kaynaklı karbon emisyonunda 20 ppm (milyonda bir birim- parts per million) civarında bir artıştan sorumlu olduklarını ve 2010 yılına kadar önlerine koyacakları ciddi bir azaltım hedefiyle bile 20 ppm olan artışı ancak 15 ppm'e indirebileceklerini öngörmüşlerdir. Böylece gelişmiş ülkelerin Kyoto hedeflerine ulaşmalarının zor olduğunu söylemişlerdir. Gupta vd. (2003), karbon emisyonu azaltımının ülkelerin oldukça değişken olan bir takım ekonomik ve politik mekanizmalara bağlı olduğunu ve bu durumun Kyoto hedeflerine ulaşmayı belirsizleştirdiğini savunmuştur. Erdoğdu (2010) Türkiye'nin Kyoto hedeflerine ulaşma çabalarının gerçekçi olup olmadığıı tartş̧ıştır. Li ve Lin (2013) analiz ettikleri 110 ülkenin küresel karbon emisyon yakınsamasını (carbon emission convergence) hesaplamışlar ve tüm örneklem için mutlak bir yakınsama olmadığını ancak gelir düzeylerine göre gruplandığında bazı ülkeler için mutlak bir yakınsamanın söz konusu olabileceğini göstermişlerdir.

Literatürdeki çalışmalar çoğunlukla; Kyoto protokolünün emisyon azaltımına etkisinden ziyade, anlaşmanın ülkelerdeki ekonomik etkileri üzerinedir. Viguier vd. (2003), Kyoto'nun Avrupa Birliği ülkelerine maliyeti ve ekonomik etkilerini incelemiştir. Van Vuuren vd. (2006), Kyoto protokolünün Avrupa'daki bölgesel hava kirliliği politikalarını ve iklim değişikliği üzerine etkisini araştırmıştır. Dagoumas vd. (2006), Kyoto protokolünün ülke ekonomileri üzerine etkilerini içeren birçok senaryo üzerinde çalışmıştır. Aichele ve Felbermayr (2012), Kyoto'nun ülkelerdeki yatııı ve tüketim harcamalarına olan etkisini ortaya koymuştur. Huang ve Barker (2012), gayri safi yurt içi hasıla ve karesini bağımsız değişkenler olarak almışlar, emisyonların kısa ve uzun dönem denge tahminlerini yapmışlardır. Rahman ve Kirkman (2015), Kyoto protokolünün önerdiği emisyon azaltım hedeflerinin maliyet hesaplarını yapmışlardır.

Yukarıda bahsedilen çalışmaların aksine mevcut çalışmanın amacı, Kyoto Annex ülkeleri yardımıyla küresel karbon emisyonu serilerinde Kyoto protokolünün anlamlı yapısal kırılmalar yaratıp yaratmadığını, emisyonların durağan ya da durağan dışı bir seyir takip edip etmediklerini inceleyerek Kyoto protokolünün emisyonlar üzerinde anlamlı etkilerinin olup olmadığını ortaya çıkarmaktır.

\section{Veri ve Ekonometrik Yöntem}

Çalışmada verilerine ulaşılabilen 26 Kyoto ülkesi için kişi başına düşen karbon emisyon miktarı serileri Dünya Bankası veri tabanından 1960-2013 dönemi boyunca yıllık olarak temin edilmiştir. Burada eksik verisi bulunan Kyoto ülkeleri analiz dışında bırakılmakta ve analize dahil edilen ülkeler Tablo 3'te gösterilmektedir.

Kyoto protokolüne imza atan ülkeler dünyanın geleceği için ortak bir paydada fikir birliğine varmışlardır. Protokole göre, ülkeler kademeli olarak sera gazı miktarlarını azaltmak ile yükümlü olmuşlardır. Dolayısıyla Kyoto ülkeleri karbon emisyon miktarları açısından birbirlerinden etkilenmesi beklenmektedir. Ayrıca Kyoto protokolü imzalanma aşamasına gelmeden ve imzalandıktan sonra protokolün getirdiği zorunlu 
sebeplerden dolayı ülkelerin karbon emisyon serilerinde aşağı doğru bir trend başlayacağı beklenmektedir. Yani protokolden sonra karbon emisyon serilerinde bir veya birden çok kırılma olması beklenmektedir. Seride ortaya çıkan yapısal kırılmaların varlığı halinde klasik birim kök testleri geçerliliğini koruyamamaktadır. Zaman serilerinde yapısal kırılmayı dikkate almadan yapılan birim kök testlerinde, gerçekte deterministik bir trend içeren çoğu iktisadi ve finansal zaman serileri yanlış olarak stokastik trende sahipmiş gibi görünmektedir (Çağlar, 2015). Dolayısıyla teorik olarak beklentilere uygun olan yapısal kırılmaları ve yatay kesit bağımlılığını birlikte dikkate alan Carrion-i-Silvestre (2005) ve Carrion-i-Silvestre vd.'nin (2005) önerdiği test kullanılacaktır. Ayrıca çalışmada hem karşılaştırma yapmak amacı ile hem de kırılmaların anlamlılığını test etmek amacıyla birinci nesil panel birim kök testlerine de yer verilecektir. Birim kök analizinde sabitli model değil de sabitli ve trendli model tercih edilmiştir. Kyoto gibi anlaşmaların amacı karbon serilerinin trendini azalan yönde değiştirmek olduğundan serilerin ortalamalarında (düzeylerinde) bir kırılmadan çok trendlerinde kırılmaların olması yapılan anlaşmanın başarısını gösterecektir. Örneğin Kyoto anlaşmasından sonra ülkelerin karbon serilerinde azalan (aşağıya doğru) bir trendin meydana gelmesi anlaşmanın başarılı olacağı anlamına gelecektir. Sonuç olarak birim kök süreci sadece sabitli ve trendli modeller üzerinden analiz edilmiştir.

\subsection{Pankpss Test Metodolojisi}

Literatürde Panel Kpss testi olarak bilinen ve Carrion-i-Silvestre (2005) ve Carrion-i-Silvestre $v d$. (2005) tarafindan geliştirilen bu test, veri oluşturma sürecinde birden çok kırılmayı (değişimi) dikkate almaktadır. Ayrıca paneli bir araya getiren serilerin ortalamalarında ve trendlerindeki kırılmayı dikkate almaktadır. Birden fazla serilerin bir araya getirilmesi ile oluşturulan panelde, her bir yatay kesit birim için farklı zamanlarda ve farklı sayılarda kırılmalar bulmaktadır. Ayrıca hem paneli oluşturan her bir yatay kesit için bireysel durağanlık testi yapılabilmekte hem de panelin tümü için ortak durağanlık testi yapılabilmektedir. Bu testte KPSS tipi testlerde olduğu gibi sıfir hipotezi durağanlık ile gösterilmektedir. Güloğlu ve İspir (2011) çalışmasındaki pankpss yaklaşımı takip edilerek şu şekilde açıklanmaktadır:

Testin başlangıç veri oluşturma süreci aşağıdaki gibi bir model olabilir.

$$
y_{i t}=\beta_{i t}+\delta_{i t}+u_{i t} \quad i=1,2, \ldots, N \text { ve } t=1,2, \ldots, T
$$

Bu denklemde $\beta_{i t}$,

$$
\beta_{i t}=\sum_{k=1}^{m_{i}} \varphi_{i, k} D\left(T_{b, k}^{i}\right)_{t}+\sum_{k=1}^{m_{i}} \theta_{i, k} D U_{i, k t}+\beta_{i, t-1}+\varepsilon_{i, t}
$$

olarak ifade edilebilmektedir. Burada $\varepsilon_{i, t} \sim i . i . d\left(0, \sigma_{\varepsilon, i}^{2}\right)$ ve $\beta_{i 0}=\beta_{i}{ }^{\prime}$ dir ve bir sabiti göstermektedir. (2) numaralı denklemin kukla değişkenleri ise $T_{b, k}^{i} \mathrm{i}^{\prime}$ nci yatay kesit için $\mathrm{k}^{\prime} ı n c ı$ kırılma zamanı olmak üzere aşağıdaki gibi oluşturulmaktadır:

$D\left(T_{b, k}^{i}\right)_{t}=1 t=T_{b, k}^{i}+1$ için; 0 diğer durumlar.

$D U_{i, k, t}=1 t>T_{b, k}^{i}$ için; 0 diğer durumlar.

Modelde, $\mathrm{k}=1,2, \ldots, \mathrm{m}$ olarak gösterildiği için $\mathrm{m}$ tane kırılmanın (değişimin) gerçekleşmesine olanak sağlamakta ve Hadri testinde olduğu gibi $u_{i, t}$ ve $\varepsilon_{i, t}{ }^{\prime}$ nin birbirlerine göre bağımsız olarak dağıldığı öne sürülmektedir. Ancak sıfir hipotezi, Hadri testinde olduğundan biraz farklı olarak aşağıdaki gibi gösterilmektedir:

$H_{0}: \sigma_{\varepsilon, i}^{2}=0(\mathrm{i}=1,2, \ldots, \mathrm{N})$

Buradan, sıfir hipotezi dikkate alınarak denklem (2) aşağıdaki gibi yeniden düzenlenebilir:

$$
y_{i, t}=\beta+\sum_{k=1}^{m_{i}} \varphi_{i, k} D U_{i, k, t}+\sum_{k=1}^{m_{i}} \theta_{i, k} D T_{i, k, t}^{*}+\delta_{i} t+u_{i, t}
$$

Burada, $D T_{i, k, t}^{*}=t-T_{b, k}^{i} \mathrm{t}>T_{b, k}^{i}$ için, 0 diğer durumlar olarak gösterilmektedir. 
(3) numaralı denklemde, a) paneldeki serilerin bireysel kırılma etkilerini (ortalamadaki değişimin kırılmadan ileri geldiği durum), b) kalıcı olmayan etkileri, $\left.\left(\beta_{i} \neq 0 i c ̧ i n\right), c\right)$ kalıcı olmayan kırılma etkilerini $\left(\theta_{i, k} \neq 0 i c ̧ i n\right)$ yani paneldeki bireysel trendlerin değişimini ele almaktadır.

Bu testte şu üç olgu dikkate alınmaktadır: a) Serilerdeki değişimler veya kırılmalar paneli bir araya getiren her bir seri için değişik etki gösterir. Bu etkiler $\theta_{i, k}$ ve $\varphi_{i, k}$ ile hesaplanmaktadır. b) Kırılmalar paneli oluşturan her bir seri için farklı bir zamanda (tarihte) olabilir. c) Paneldeki kırıma (değişim) sayısı seriden seriye farklı olabilir. Dahası paneldeki serilerin birbirlerinden etkilenmediği durumunu gösteren yatay kesit bağımlılığı ise, Maddala ve Wu (1999) tarafindan geliştirilen parametrik olmayan bootstrap metoduyla iyileştirilmektedir.

Uzun dönem varyansın sabit olduğu varsayımı altında $H_{0}: \sigma_{\varepsilon, i}^{2}=0(i=1,2, \ldots N)$ durağanlık sıfir hipotezi $L M_{H o m}$ istatistiği ile test edilebilir:

$$
L M_{H o m}(\lambda)=N^{-1} \sum_{\dot{I}=1}^{N}\left(\widehat{\omega}^{-2} T^{-2} \sum_{t=1}^{T} S_{i, t}^{2}\right)
$$

Burada, $S_{i t}=\sum_{j=1}^{t} u_{i j}$ ve $N^{-1} \sum_{i=1}^{N} \widehat{\omega}^{2} \widehat{\omega}^{2}=\lim _{t \rightarrow \infty} T^{-1} s_{i, T}^{2}$ dir.

4 numaralı denklemde $\left(\hat{u}_{i, t}\right)$, En Küçük Kareler kalıntılarını gösterirken, $\omega_{i}^{2}$ ise $u_{i t}$ 'nin uzun dönem varyansının tutarlı bir tahmincisini göstermektedir. Burada, $\lambda$ terimi LM sınama istatistiğinin kırılma tarihlerine (zamanlarına) bağı olarak hesaplanmaktadır. Paneldeki her bir yatay kesit birimi için $\lambda_{i}$ vektörü aşă̆ıdaki gibi gösterilmektedir:

$$
\lambda_{i}=\left(\lambda_{i, 1}, \ldots, \lambda_{i, m i}\right)^{\prime}=\left(T_{b, 1}^{i} / T \ldots T_{b, m i}^{i} / T\right)^{\prime}
$$

Sonuç olarak, $\lambda_{i}$ paneldeki her bir yatay kesit birimi için kırılmaların tüm gözlemlere $(T)$ oranla göreli yerini ifade etmektedir. Uzun dönem varyansın yatay kesit birimleri arasında değişmesine izin verildiğinde ise $L M_{\text {Het }}$ istatistiği şu şekilde ifade edilebilir:

$$
L M_{H e t}(\lambda)=N^{-1} \sum_{\dot{I}=1}^{N}\left(\widehat{\omega}_{i}^{-2} T^{-2} \sum_{t=1}^{T} S_{i, t}^{2}\right)
$$

LM istatistikleri şu şekilde standartlaştırımıştır.

$$
Z(\lambda)=\frac{\sqrt{N}(L M(\lambda)-\bar{\xi})}{\bar{\zeta}} \sim N(0,1)
$$

$Z(\lambda)$ istatistiğinin önce $T \rightarrow \infty$ sonra $N \rightarrow \infty$ için asimtotik olarak standart normal dağılım özelliği gösterdiği kanıtlanmıştır. Burada $\bar{\xi}$ ve $\bar{\zeta}$ beklenen değer ve varyansların her bir yatay kesit için aritmetik ortalamasıdır. Başka bir ifadeyle, $\bar{\xi}=N^{-1} \sum_{i=1}^{N} \xi_{i}$ ve $\bar{\zeta}=N^{-1} \sum_{i=1}^{N} \zeta_{i}^{2}$ olmaktadır.

$Z(\lambda)$ değişkeni için bireysel beklenen değer $\left(\xi_{i}\right)$ ve varyanslar $\left(\zeta_{i}^{2}\right)$, şu şekilde ölçülebilir (Carrion-iSilvestre (2005) ve Carrion-i-Silvestre $v d$. (2005)):

$\xi_{i}=A \sum_{k=1}^{m_{i}+1}\left(\lambda_{i, k}-\lambda_{i, k-1}\right)^{2}$ ve $\left(\zeta_{i}^{2}=B \sum_{k=1}^{m_{i+1}}\left(\lambda_{i, k}-\lambda_{i, k-1}\right)^{4}\right.$

$\beta_{i}=\theta_{i, k}=0$ kısıtlaması altında $\lambda_{i, k}=0, \lambda_{i, m+1}=1, \mathrm{~A}=1 / 6$ ve $\mathrm{B}=1 / 45$ alırken $\beta_{i} \neq \theta_{i, k} \neq 0$ için $\mathrm{A}=1 / 15$ ve $\mathrm{B}=11 / 63000$ olarak hesaba katilmaktadır.

7 numaralı denklemdeki $Z(\lambda)$ istatistiğinin hesaplanması için kırılma tarihlerinin (zamanlarının) bilinmesi zorunluluğu vardır. Carrion-i-Silvestre ve diğerleri kırılmaları içsel olarak belirlemekte (veri oluşturma süreci içerinde test kırılma tarihini belirleyebilmektedir) ve bu amacı gerçekleştirmek için, Bai ve Perron'un (1998) hata kareler toplamının global minimizasyonu sürecini takip etmektedirler. Bai ve Perron (1998) sürecinde kırılma tarihlerinin tahmini olarak $\left(T_{b, 1}^{i}, \ldots, T_{b, m i}^{i}\right)$ dizisi için denklem 3 'den elde edilen hata 
kareler toplamını (RSS) minimize eden argüman seçilmektedir. Bu süreç matematiksel olarak aşağıdaki gibi ifade edilebilir (Güloğlu ve İspir, 2011):

$$
\left(\widehat{T}_{b, 1}^{i}, \ldots, \widehat{T}_{b, m i}^{i}\right)=\arg \min _{T_{b, 1}^{\prime}, \ldots, T_{b, m i}^{\prime}} R S S\left(T_{b, 1}^{i}, \ldots, T_{b, m i}^{i}\right)
$$

Mümkün tüm $m_{i} \in m^{\max } i=(1,2, \ldots, N)$ değerleri için kırılma tarihleri elde edildikten sonra, paneldeki her bir yatay kesit için uygun kırılma sayısı seçilerek m'nin optimal değeri belirlenir. Bai ve Perron (1998) burada iki farklı süreç ileri sürmektedir. Birincisi, Liu-Wu ve Zidek (1997) ile literatüre giren değiştirilmiş Schwarz bilgi kriterlerine (LWZ) dayalıdır. İkincisinde ise, kırılma sayısını belirlemek üzere ard arda $\mathrm{F}$ istatistiğinin hesaplanması zorunluluğudur. Fakat, Bai ve Perron (1998) F istatistiğinin asimtotik dağılımını sadece trend içermeyen model için geliştirmiş olmalarına rağmen ikinci sürecin kullanılmasını önermektedirler. Carrion-i-Silvestre vd. (2005) trendsiz model için ikinci süreci tercih ederken, trendli regresyon için ise bilgi kriterlerine dayalı olan ikinci süreci dikkate almaktadırlar. (Güloğlu ve İspir, 2011).

\section{Ampirik Bulgular}

Çalışmada yapısal kırılmayı ve yatay kesit bağımlıı̆ı̆ını dikkate alan pankpss testinin kullanıımasının amaçları yukarıda açıklanmaktadır. Bu bağlamda kırılmaların anlamlı olup olmadığını belirleyebilmek için öncelikle birinci nesil panel birim kök testleri sonuçları Tablo 1'de gösterilmektedir.

Tablo 1. Birinci Kuşak Panel Birim Kök Test Sonuçları

\begin{tabular}{|l|l|l|}
\hline \multirow{2}{*}{ Test } & \multicolumn{2}{|c|}{ Sabit ve Trendli } \\
\cline { 2 - 3 } & Test-ist & -değeri \\
\hline Levin, Li\&Chu (LLS) ${ }^{*}$-ist. & 0.525 & 0.700 \\
\hline Im, Pesaran ve Shin (IPS) W-ist. & 2.913 & 0.998 \\
\hline Fisher- ADF- $\chi^{2}$ & 44.260 & 0.768 \\
\hline Fisher- PP- $\chi^{2}$ & 43.708 & 0.786 \\
\hline Breitung t-ist & 7.865 & 0.999 \\
\hline Hadri Z ist. (sabit varyans) & 12.431 & 0.000 \\
\hline Hadri Z ist. (değişen varyans) & 12.026 & 0.000 \\
\hline
\end{tabular}

Not: LLC, IPS, Fisher- ADF ve Fisher-PP testleri için gecikme uzunluğu Schwarz kriterine göre ve Hadri testi için ise Newey-West kriterine göre belirlenmiştir.

Tablo 1'de sabit ve trendli model için, Levin, Li ve Chu, (2002), Im, Pesaran ve Shin (2003), Maddala ve Wu (1999) tarafindan önerilen Fisher- ADF ve Fisher- PP ve Breitung testlerine göre panelin birim kök içerdiği sıfir hipotezi kabul edilmektedir. Hadri (1999) tarafindan önerilen ve sabit ve değişen varyans durumlarına göre ayrılan iki farklı test istatistiğine göre ise panelin durağan olduğunu söyleyen sıfir hipotezi reddedilmektedir. Hadri (1999) testinde görüldüğü üzere ters hipotez geçerli olmaktadır. Sonuç olarak, yatay kesit bağımlıı̆ını dikkate almayan birinci nesil panel birim kök testlerine göre karbon emisyonu serisi birim kök içerdiği bulgusuna ulaşılmaktadır.

Analiz sonuçlarının sapmasız ve tutarlı olabilmesi için öncelikle ülkeler arası yatay kesit bağımlıı̆ının test edilmesi gerekmektedir. Literatürde yaygın olarak kullanılan birkaç test bulunmaktadır. Bunlardan birincisi, Breusch ve Pagan (1980) tarafindan geliştirilen T>N için; LM istatistiği CDLM1 ve ikincisi ise Pesaran (2004) tarafindan geliştirilen ve $N$ ve T'nin büyük olduğu durumlarda kullanılan CDLM2 ve $N>T$ olduğu durumlarda kullanılan $C D$ test istatistikleridir. Çalışmada $N=26$ ve $T=54$ olduğu için CDLM1 test istatistiğinin sonucu daha güvenilir olacaktır. Tablo 2'de yatay kesit bağımlılığı test sonuçları gösterilmektedir. 
M. Mert-A. E. Caglar

Tablo 2. Yatay kesit Bağımlılığı Test Sonuçları

\begin{tabular}{|l|l|l|}
\hline & \multicolumn{2}{|l|}{ Sabit ve Trendli } \\
\hline & Test-ist & $P$-değeri \\
\hline CD LM1 & 569.161 & 0.000 \\
\hline CD LM2 & 9.577 & 0.000 \\
\hline CD & -1.932 & 0.027 \\
\hline
\end{tabular}

Tablo 2' de hem Breusch ve Pagan (1980) hem de Pesaran (2004) testlerinin sonuçları sabit ve trendli model için gösterilmektedir. Yatay kesit bağımsızlığının olmadığını belirten sıfır hipotezi CDLM1 test istatistiğinin $P$-değerine $(0.000<0.01)$ göre $\% 1$ yanılma düzeyinde reddedilmektedir. Dolayısıyla teorik olarak beklentilerin karşılandığı görülmektedir. Yani CDLM1 test istatistiğine göre ülkelerin karbon emisyon serileri birbirlerinden etkilenmektedirler. Dolayısıyla yapısal kırılmaları ve yatay kesit bağımlılığını dikkate alan Carrion-i-Silvestre (2005) ve Carrion-i-Silvestre vd. (2005) tarafindan önerilen pankpss testinin kullanılması uygun olacaktır. Tablo 3'de Pankpss test sonuçları gösterilmektedir.

Tablo 3. Pankpss Test Sonuçları

\begin{tabular}{|c|c|c|c|c|c|c|c|c|c|c|}
\hline \multicolumn{11}{|c|}{ Panel A: Yapısal Kırılma Tarihleri ve Bireysel Pankpss Sonuçları } \\
\hline \multirow{2}{*}{ Ülkeler } & \multirow{2}{*}{ KPSS } & \multirow{2}{*}{$m$} & \multirow{2}{*}{$T B_{1}$} & \multirow{2}{*}{$T B_{2}$} & \multirow{2}{*}{$T B_{3}$} & \multirow{2}{*}{$T B_{4}$} & \multirow{2}{*}{$T B_{5}$} & \multicolumn{3}{|c|}{ Kritik Değerler (\%) } \\
\hline & & & & & & & & 90 & 95 & 99 \\
\hline ABD & 0.037 & 3 & 1969 & 1980 & 2004 & & & 0.121 & 0.156 & 0.215 \\
\hline Avusturalya & 0.031 & 2 & 1979 & 2005 & & & & 0.090 & 0.119 & 0.179 \\
\hline Avusturya & 0.051 & 3 & 1969 & 1979 & 2002 & & & 0.121 & 0.158 & 0.227 \\
\hline Belçika & 0.111 & 3 & 1974 & 1982 & 1997 & & & 0.122 & 0.155 & 0.217 \\
\hline Bulgaristan & 0.038 & 3 & 1969 & 1989 & 2000 & & & 0.123 & 0.157 & 0.228 \\
\hline Danimarka & 0.023 & 2 & 1970 & 1995 & & & & 0.096 & 0.126 & 0.187 \\
\hline Finlandiya & 0.029 & 2 & 1980 & 2002 & & & & 0.094 & 0.127 & 0.189 \\
\hline Hollanda & 0.037 & 3 & 1969 & 1981 & 1996 & & & 0.123 & 0.158 & 0.225 \\
\hline İngiltere & 0.027 & 2 & 1973 & 2004 & & & & 0.096 & 0.124 & 0.180 \\
\hline İrlanda & 0.112 & 3 & 1970 & 1985 & 2000 & & & 0.128 & 0.159 & 0.218 \\
\hline İspanya & 0.041 & 5 & 1968 & 1976 & 1988 & 1996 & 2005 & 0.220 & 0.259 & 0.344 \\
\hline İsveç & 0.042 & 2 & 1968 & 1981 & & & & 0.098 & 0.132 & 0.203 \\
\hline İsviçre & 0.084 & 1 & 1973 & & & & & 0.103 & 0.126 & 0.178 \\
\hline italya & 0.029 & 3 & 1973 & 1981 & 2005 & & & 0.108 & 0.143 & 0.209 \\
\hline İzlanda & 0.030 & 2 & 1980 & 2004 & & & & 0.095 & 0.127 & 0.192 \\
\hline Japonya & 0.061 & 2 & 1969 & 1989 & & & & 0.094 & 0.125 & 0.185 \\
\hline Kanada & 0.022 & 4 & 1971 & 1981 & 1989 & 2004 & & 0.166 & 0.206 & 0.273 \\
\hline Lüksemburg & 0.054 & 4 & 1974 & 1982 & 1994 & 2003 & & 0.168 & 0.199 & 0.274 \\
\hline Macaristan & 0.164 & 3 & 1983 & 1991 & 2005 & & & 0.118 & 0.155 & 0.222 \\
\hline Norveç & 0.029 & 1 & 1989 & & & & & 0.089 & 0.116 & 0.181 \\
\hline Polonya & 0.019 & 4 & 1968 & 1980 & 1989 & 1998 & & 0.165 & 0.201 & 0.282 \\
\hline Portekiz & 0.035 & 2 & 1988 & 2001 & & & & 0.107 & 0.138 & 0.200 \\
\hline Romanya & 0.035 & 3 & 1979 & 1989 & 2001 & & & 0.126 & 0.158 & 0.220 \\
\hline Türkiye & 0.041 & 2 & 1978 & 2000 & & & & 0.097 & 0.132 & 0.193 \\
\hline Yeni Zelanda & 0.027 & 3 & 1978 & 1989 & 2001 & & & 0.126 & 0.162 & 0.222 \\
\hline Yunanistan & 0.030 & 2 & 1972 & 2005 & & & & 0.096 & 0.121 & 0.176 \\
\hline \multicolumn{11}{|c|}{ Panel B: Panel Birim Kök Sonuçları } \\
\hline \multicolumn{3}{|c|}{ Model } & \multicolumn{4}{|c|}{ Test ist. } & \multicolumn{4}{|c|}{$P$-değeri } \\
\hline \multicolumn{3}{|c|}{$L M(\lambda)($ hom $)$} & \multicolumn{4}{|c|}{7.475} & \multicolumn{4}{|c|}{0.000} \\
\hline \multicolumn{3}{|c|}{$L M(\lambda)($ het $)$} & \multicolumn{4}{|c|}{12.578} & \multicolumn{4}{|c|}{0.000} \\
\hline \multicolumn{11}{|c|}{ Panel C: Bootstrap Kritik Değerler (\%) } \\
\hline \multicolumn{2}{|c|}{ Model } & \multicolumn{3}{|c|}{\begin{tabular}{l|l}
90 \\
\end{tabular}} & \multicolumn{3}{|c|}{95} & \multicolumn{3}{|c|}{99} \\
\hline$L M(\lambda)(h$ & & & 16.409 & & & 17.988 & & & 21.709 & \\
\hline$L M(\lambda)($ & & & 25.360 & & & 27.547 & & & 31.902 & \\
\hline
\end{tabular}


Tablo 3 incelendiğinde, Panel A kısmında sabit ve trendli model için bireysel panel birim kök sonuçları gösterilmektedir. Sonuçlara göre, ekonometrik analizde sıkça kullanılan \%1 yanılma düzeyinde, bütün ülkelerde bireysel olarak durağanlık hipotezi kabul edilmektedir. Ayrıca; ülkelerin bireysel olarak kırılma tarihlerini genel olarak ikiye ayırırsak, kırılmaların 1969-1970'li yılların başında başlamakta ve 2004-2005 yılları etrafinda son bulmakta olduğu görülmektedir. 70 'li yılların başında meydana gelen petrol krizinin küresel anlamda karbon emisyonlarını etkilediği ve emisyonlardaki son kırılma tarihleri olan 2005 yılı civarı Kyoto anlaşmasının yürürlüğe girdiği tarih olduğundan bu anlaşmanın etkisi olarak bu kırıma zamanının ortaya çıktığı söylenebilir. Bir olayın etkisinin ekonometrik analizlerde olayın yürürlüğe girdiği tarihte gerçekleşmesi beklenmemelidir. Yürürlülük tarihinden önce ya da sonra da kırılmalar gerçekleşebilir. Kyoto anlaşması 1997 yılında imzalandığı için yürürlülük tarihi olan 2005 yılından önce meydana gelen kırılmalar da Kyoto'nun etkisiyle gerçekleşmiş olabilir. Dolayısıyla 1997-2005 yılları arasında gerçekleşen kırılmalar Kyoto'nun etkisiyle gerçekleşebilir. Ayrıca sonuçlardan da görüldüğü üzere 2000 yılının başında gerçekleşen kırılmalar, 2001 yılında 11 Eylül sonrası küresel GSYiH'da oluşan durgunluğun etkisini gösterebilir çünkü, karbon emisyonları ile ekonomik büyüme arasında anlamlı ilişkilerin olduğunu gösteren bir çok çalışma bulunmaktadır (Mert ve Bölük, 2016; Bölük ve Mert, 2014; 2015).

Tablo 3'ün Panel B kısmında ise, 26 Kyoto ülkesi için ortak panel durağanlık sonuçları asimtotik kritik değerleri ile birlikte gösterilmektedir. Fakat yatay kesit bağımlılığı hipotezi bütün yanılma düzeylerinde reddedildiği için Panel B'deki LM test istatistikleri Panel C'deki Bootstrap kritik değerleri ile karşıllaştrılacaktır. Bütün yanılma düzeyleri dikkate alındığında hem sabit varyans hem de değişen varyans durumları altında LM test istatistikleri, bootstrap kritik değerlerinden $[(L M(\lambda)($ hom $)=7.475<$ bootstrap kritik değerleri), $(L M(\lambda)($ het $)=12.578<$ bootstrap kritik değerleri $)]$ küçük olduğu için durağanlığı gösteren sıfir hipotezi reddedilememektedir. Bu sonuçlar yapısal kırılmaların ve yatay kesit bağımlılığının dikkate alınmasının oldukça önemli olduğunu göstermektedir. Çünkü yapısal kııılmaları ve yatay kesit bağımlılı̆ını dikkate almayan birinci nesil panel birim kök test sonuçlarında karbon emisyonu serisi durağan dışı bulunmuştu. Aksine pankpss testi ile karbon emisyonu serisinin durağan olduğu görülmüştür. Buradan da kırılmaların anlamlı bir etkiye sahip olduğu görülmektedir.

\section{Sonuç}

Çalışmada Kyoto protokolünün karbon emisyonlarını azaltım noktasında anlamlı bir etkisinin olup olmadığı yapısal kırılmaları ve yatay kesit bağımlıı̆ını dikkate alan pankpss panel birim kök testi ile araştrılmıştr. Öncelikle birinci nesil birim kök testleri yapılmış ve incelenen 26 Annex ülkesinden oluşan Kyoto panelinde kişi başı karbon salımı serileri durağan dışı bulunmuştur. Daha sonra yatay kesit bağımlılığı test edilmiş ve yatay kesit bağımlılığının olmadığını ifade eden sıfir hipotezi reddedilmiştir. Sonuç olarak yatay kesit bağımlılığı altında yapısal kırılmaları da dikkate alan pankpss birim kök testi uygulanmıştır. Bu test hem uzun dönem hata varyansının sabit olduğu hem de değişken olduğu durum için de uygulanmıştır. Her iki durum için de; sabit ve trendli model için emisyon serilerinden oluşan panel durağan bulunmuştur. Ayrıca kırılma zamanları incelenen ülkeler için, 26 Kyoto ülkesinin 19'unda, Kyoto antlaşmasının etkisinin gözlemlenebileceği 1997-2005 yılları arasında kırılmalar görülmektedir. Böylelikle Kyoto antlaşmasının karbon serilerinde istatistiksel olarak anlamlı kırılmalar yaratarak etkisinin önemli olduğu söylenebilir.

Modelde yatay kesit bağımlıı̆ıının olması ülkelerin atmosfere saldıkları karbon miktarlarının birbirlerinden etkilendiği anlamına gelmektedir. Bu ise küresel iklim değişikliği anlaşmalarında ülkeler arasında yaşanan anlaşmazlıkları ve birtakım krizleri destekler niteliktedir. Genellikle ülkeler başka bir ülkenin azaltımını örnek almak yerine emisyon arttrımlarını örnek almakta ve hatta bazen anlaşmadan çekilmektedirler.

Birinci nesil birim kök testinin karbon serilerinden oluşan paneli durağan dışı bulup, yapısal kırılmaları dikkate alan pankpss testinin durağan bulması serilerde anlamlı yapısal kırılmalar olduğunu göstermektedir. Ancak ülkelerin performansları ve ne ölçüde karbon azaltımlarının olduğu kullanılan yöntem gereği belirlenemediğinden Kyoto protokolünün hedefleri doğrultusunda başarılı olup olmadığı konusunda bir sonuca varılamaması çalışmanın önemli bir kısıtını oluştursada; EK'de verilen ülkelere ait kişi başı $\mathrm{CO}_{2}$ salımı grafiklerinden de anlaşılacağı üzere, Kyoto'nun yürürlüğe girdiği 2005 yılından sonra birçok ülke için salımların 
azalma eğiliminde olduğu gözlenmektedir. Bundan sonraki çalışmalarda, en azından emisyon serilerindeki kırılmalardan sonra trendin negatif ya da pozitif olarak nasıl ve ne ölçüde değiştiği istatistiksel olarak incelenebilir ve böylelikle Kyoto ülkelerinin performanslarına yönelik bir takım sonuçlar elde edilebilir. $\mathrm{CO}_{2}$ salımlarının küresel ısınmaya ve sonuç olarak iklim değişikliğine yol açtı̆ını destekleyen birçok çalışmanın olması ve Kyoto anlaşması tarzı küresel anlaşmaların iklim değişikliğini önlemek açısından küresel anlamda yapılacak en acil çözümler olması ışı̆ında yapılan çalışmadan elde edilen bulgular, tüm ülkelerin Paris anlaşmasını sahiplenerek azaltım hedeflerini gerçekleştirmelerinin önemini ayrıca ortaya koymaktadır.

En iyi bilgimiz dahilinde Kyoto protokolünün etkinliğini birim kök analizi ile araştıran herhangi bir çalışma bulunmamaktadır. Bu çalışma ile Kyoto protokolünün karbon serilerinde anlamlı kırılmalara yol açtı̆ı ve sonuç olarak etkisinin istatistiksel olarak anlamlı olduğu sonucuna ulaşılmıştır.

\section{Son Notlar}

1. Bu çalışma, Beşinci Anadolu Uluslararası iktisat Kongresi'nde (EconAnadolu2017) sözlü olarak sunulan çalışmanın yeniden gözden geçirilmiş ve genişletilmiş halidir.

\section{Kaynaklar}

Aichele, R., \& Felbermayr, G. (2012). Kyoto and the carbon footprint of nations. Journal of Environmental Economics and Management, 63(3), 336-354.

Almeida, E., \& Carvalho, T. S. (2009). The global environmental Kuznets Curve and the Kyoto Protocol. Department of Economics and Finance, Federal University of Juiz de Fora. Discussion Paper No: 36036, 330.

Apergis, N., \& Payne, J. (2009). CO2 emissions, energy usage, and output in Central America. Energy Policy; 37, 32823286.

Bai, J., \& Perron, P. (1998). Estimating and testing linear models with multiple structural changes. Econometrica, 66(1), 47-78.

Bastola U., \& Sapkota, P. (2015). Relationship among energy consumption, pollution emissions, and economic growth in Nepal. Energy, 80, 254-262.

Bölük, G., \& Mert, M. (2014). Fossil \& renewable energy consumption, GHGs (greenhouse gases) and economic growth: Evidence from a panel of EU (European Union) countries. Energy, 74, 439-446.

Bölük, G., \& Mert, M. (2015). The renewable energy, growth and environmental Kuznets curve in Turkey: An ARDL approach. Renewable and Sustainable Energy Reviews, 52, 587-595.

Breusch, T. S., \& Pagan, A. R. (1980). The lagrange multiplier tests and its applications to model specification in econometrics. The Review of Economic Studies, 47(1), 239-253.

Carrion-i-Silverstre, J.L. (2005). Health care expenditure and GDP: Are they broken stationary? Journal of Health Economics, 24(5), 939-854.

Carrion-i-Silverstre, J.L., Del Barrio-Castro, T., \& Lopez-Bazo, E. (2005). Breaking the panels: An application to the GDP per capita. Econometrics Journal, 8(2), 159-175.

Chandran, V.G.R., \& Tang, C.F., (2013). The impacts of transport energy consumption, foreign direct investment and income on $\mathrm{CO} 2$ emissions in ASEAN-5 economies. Renewable and Sustainable Energy Reviews, 24, 445-453.

Çağlar, A. E., \& Mert, M . (2017). Türkiye'de çevresel Kuznets Hipotezi ve yenilenebilir enerji tüketiminin karbon salımı üzerine etkisi: Yapısal kırılmalı eşbütünleşme yaklaşımı. Yönetim ve Ekonomi: Celal Bayar Üniversitesi iktisadi ve idari Bilimler Fakültesi Dergisi, 24(1), 21-38.

Çağlar, A. E. (2015). Yapısal kırılmalı birim kök testlerinin küçük örneklem özelliklerinin karşılaştırılması. Pamukkale Üniversitesi Sosyal Bilimler Enstitüsü Yüksek Lisans Tezi, Denizli.

Dagoumas, A. S., Papagiannis, G. K., \& Dokopoulos, P. S. (2006). An economic assessment of the Kyoto Protocol application. Energy Policy, 34(1), 26-39.

Erdogdu, E. (2010). Turkish support to Kyoto Protocol: A reality or just an illusion. Renewable and Sustainable Energy Reviews, 14(3), 1111-1117. 
Grossman, G. M., \& Krueger, A. B. (1991). Environmental impacts of a North American free trade agreement. National Bureau of Economic Research, Working Paper No:3914.

Grossman, G. M., \& Krueger, A. B. (1994). Economic growth and the environment. National Bureau of Economic Research, Working Paper No:4634.

Gupta, J., Olsthoorn, X., \& Rotenberg, E. (2003). The role of scientific uncertainty in compliance with the Kyoto Protocol to the Climate Change Convention. Environmental Science \& Policy, 6(6), 475-486.

Güloğlu, B., \& İspir, M.S. (2011). Doğal işsizlik oranı mı? İşsizlik histerisi mi? Türkiye için sektörel panel birim kök sınaması analizi. Ege Akademik Bakış, 11(2), 205-215.

Halicioglu, F. (2009). An econometric study of CO2 emissions, energy consumption, income and foreign trade in Turkey. Energy Policy, 37(3), 1156-1164.

Hadri, K. (1999). Estimation of a doubly heteroscedastic stochastic frontier cost function. Journal of Business \& Economic Statistics, 17(3), 359-363.

Holtz-Eakin, D., \& Selden, T. M. (1995). Stoking the fires? CO2 emissions and economic growth. Journal of Public Economics, 57(1), 85-101.

Huang, W. M., Lee, G. W., \& Wu, C. C. (2008). GHG emissions, GDP growth and the Kyoto Protocol: A revisit of Environmental Kuznets Curve hypothesis. Energy Policy, 36(1), 239-247.

Huang, Y., \& Barker, T. (2012). The Clean Development Mechanism and low carbon development: A panel data analysis. Energy Economics, 34(4), 1033-1040.

Im, K.S., Pesaran, M. H., \& Shin, Y. (2003). Testing for unit roots in heterogeneous panels. Journal of Econometrics, 115(1), 53-74.

Kivyiro, P., \& Arminen, H. (2014). Carbon dioxide emissions, energy consumption, economic growth, and foreign direct investment: Causality analysis for Sub-Saharan Africa. Energy, 74, 595-606.

Korhonen, R., \& Savolainen, I. (1999). Contribution of industrial and developing countries to the atmospheric CO 2 concentrations: Impact of the Kyoto protocol. Environmental Science \& Policy, 2(4), 381-388.

Kumazawa, R., \& Callaghan, M. S. (2012). The effect of the Kyoto Protocol on carbon dioxide emissions. Journal of Economics and Finance, 36(1), 201-210.

Levin, A., Lin, C. F., \& Chu, C. S. J. (2002). Unit root tests in panel data: asymptotic and finite-sample properties, Journal of Econometrics, 108(1), 1-24.

Li, X., \& Lin, B. (2013). Global convergence in per capita CO2 emissions. Renewable and Sustainable Energy Reviews, 24, 357-363.

Liu, J. S., Wu, S., \& Zidek, J. V. (1997). On segmented multivariate regressions. Statistica Sinica, 7, 497-525.

Lopez-Menendez, A.J., Perez, R., \& Moreno, B. (2014). Environmental costs and renewable energy: Re-visiting the Environmental Kuznets Curve. Journal of Environmental Management, 145, 168-373.

Maddala, G. S., \& Wu, S. (1999). A comparative study of unit root tests with panel data and a new simple test. Oxford Bulletin of Economics and Statistics, 61, 631-652.

Marrero, G. A. (2010). Greenhouse gases emissions, growth and the energy mix in Europe. Energy Economics, 32(6), 1356-1363.

Mert, M., \& Bölük, G. (2016). Do foreign direct investment and renewable energy consumption affect the CO2 emissions? New evidence from a panel ARDL approach to Kyoto Annex countries. Environmental Science and Pollution Research, 23, 21669-21681.

Pao, H. T., \& Tsai, C. M. (2011). Modeling and forecasting the CO2 emissions, energy consumption, and economic growth in Brazil. Energy, 36(5), 2450-2458.

Pesaran, M.H. (2004). General diagnostic tests for cross section dependence in panels. Cambridge Working Papers in Economics (CWPE), No:0435.

Rahman, S. M., \& Kirkman, G. A. (2015). Costs of certified emission reductions under the Clean Development Mechanism of the Kyoto Protocol. Energy Economics, 47, 126-141.

Sadorsky, P. (2009). Renewable energy consumption and income in emerging economies. Energy policy, 37(10), 40214028.

Selden, T. M., \& Song, D. (1994). Environmental quality and development: is there a Kuznets curve for air pollution emissions? Journal of Environmental Economics and management, 27(2), 147-162. 
Shafik, N. (1994). Economic development and environmental quality: an econometric analysis. Oxford economic papers, 757-773.

Sulaiman, J., Azman, A., \& Saboori, B. (2013). Evidence of the environmental Kuznets curve: Implications of industrial trade data. American Journal of Environmental Sciences, 9(2), 130.

Sun, L., \& Wang, M. (1996). Global warming and global dioxide emission: An empirical study. Journal of Environmental Management, 46(4), 327-343.

Swinton, J. R., \& Sarkar, A. (2008). The benefits of the Kyoto Protocol to developing countries. Environment, Development and Sustainability, 10(6), 731-743.

UFCCC, ( 2015), Kyoto Protocol, United Nations Framework Convention on Climate Change (UNFCCC) , http://unfccc.int/kyoto_protocol/items/2830.php, (Erişim Tarihi, 15 Ekim 2015).

Van Vuuren, D. P., Cofala, J., Eerens, H. E., Oostenrijk, R., Heyes, C., Klimont, Z., den Elzen, M.G.J., \& Amann, M. (2006). Exploring the ancillary benefits of the Kyoto Protocol for air pollution in Europe. Energy Policy, 34(4), 444-460.

Viguier, L. L., Babiker, M. H., \& Reilly, J. M. (2003). The costs of the Kyoto Protocol in the European Union. Energy Policy, 31(5), 459-481.

WB (2015). World Development Indicators: Energy Dependence, efficiency and carbon dioxide emissions, http://wdi.worldbank.org/table/3.8 (Erişim Tarihi, 30 Kasım 2015). 


\section{Ekler}

Ek 1. Kyoto Ülkelerinin $\mathrm{CO}_{2}$ Salımlarına Ait Zaman Yolu Grafikleri (Kyoto'nun yürürlüğe girdiği 2005 yılı grafikler üzerinde belirtilmiştir)
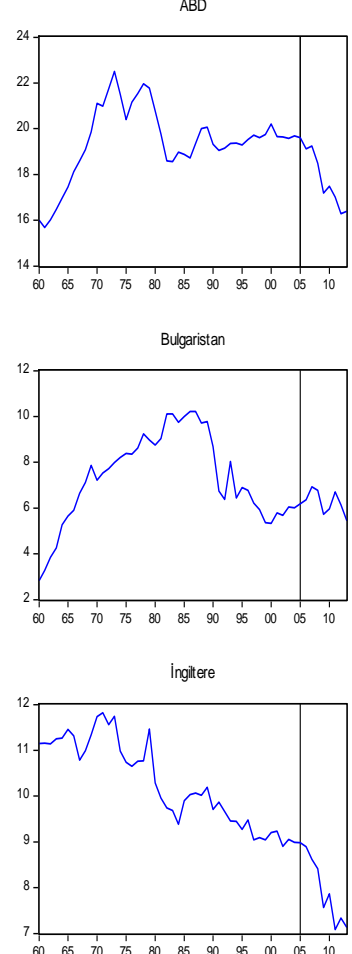

Isviçre
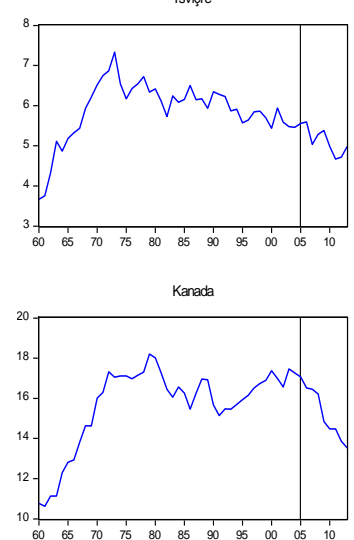

Polonya

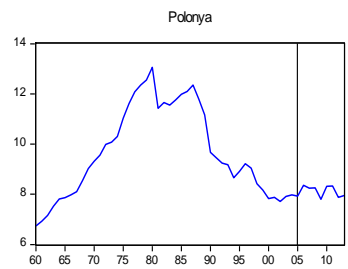

Yeni Zelanda

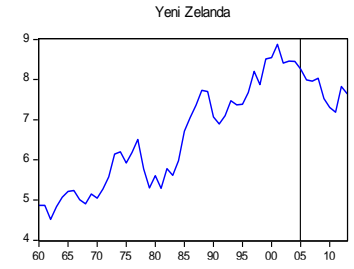

Avusturalya

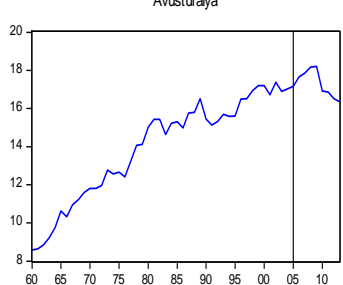

Danimarka

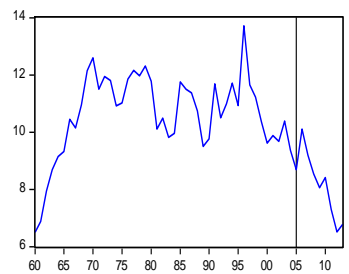

Irlanda

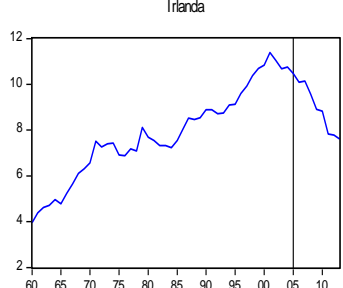

Italya

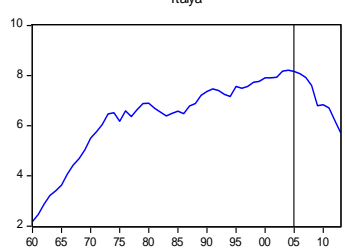

Lüksemburg

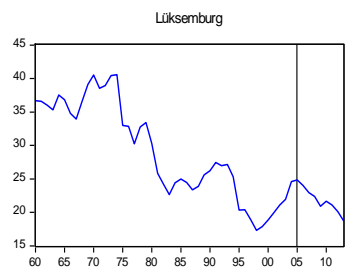

Portekiz

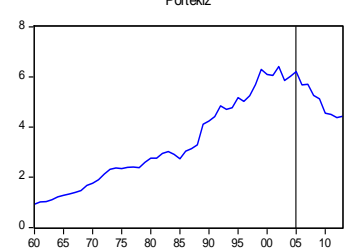

Yunanistan

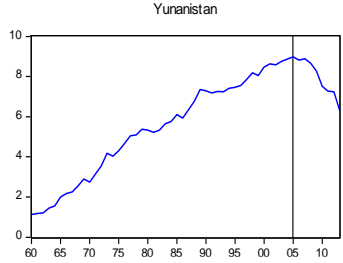

Belçka
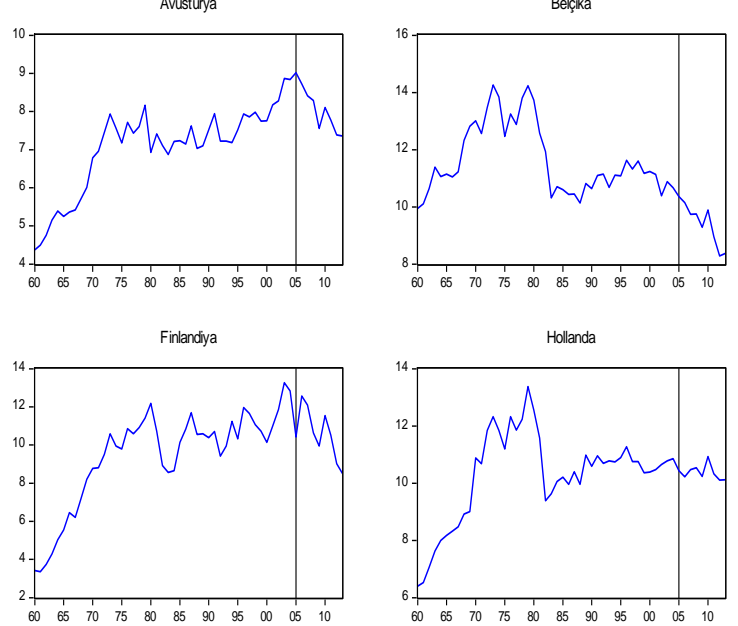

Isparya

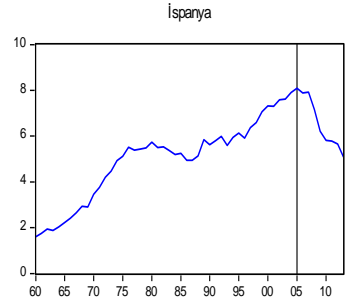

Izlanda
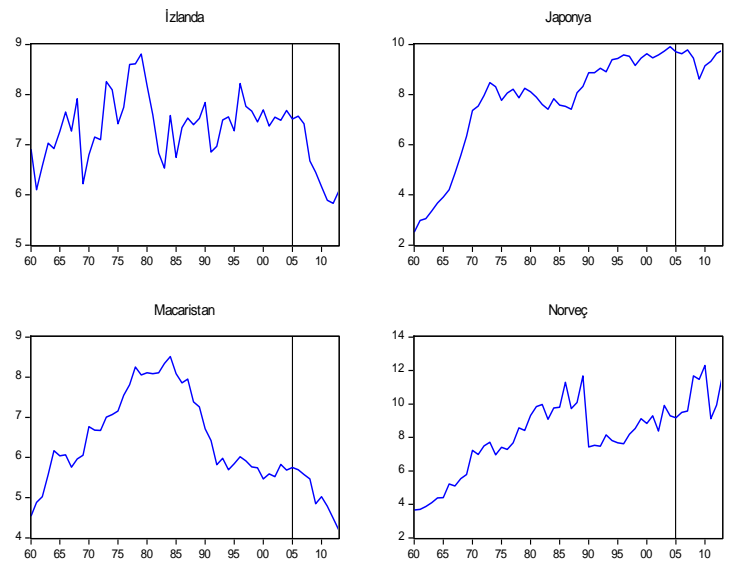

Türkiye
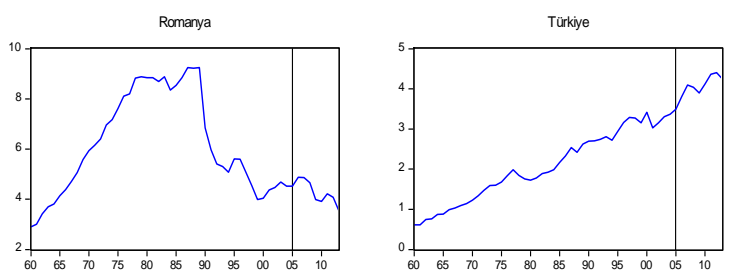